\title{
ELS COMPTES \\ DE FRA LLUÍS PONÇ \\ EN L'AMBAIXADA \\ A ENRIC IV (1463)
}

\author{
Agustí Altisent
}

Per la sentència arbitral de Baiona del 23 d'abril de 1463 , Lluís XI, erigit en àrbitre de les discrepàncies entre el rei d'Aragó i el de Castella en relació amb Catalunya, determinà que Enric IV renunciés, amb certes compensacions, al tron que la Diputació del General i el Consell de Barcelona li havien ofert i ell havia acceptat, i que Joan II respectés les Constitucions de Catalunya i la Capitulació de Vilafranca'.

Aquesta decisió, si descontentà castellans, aragonesos i catalans, deixà especialment desarmats aquells d'entre aquests darrers que estaven a favor de les autoritats del Principat, car es veien privats del rei que havien elegit després de deposar Joan II, i desproveïts de l'ajuda bèl-lica que d'aquell rei esperaven.

Amb el fi de fer pressió a Enric IV, les autoritats del Principat van decidir aleshores enviar a Castella una ambaixada formada per fra Lluís Ponç, monjo de Poblet i prior de la casa de Natzaret de Barcelona, membre del Consell, i mossèn Miquel Cardona. Aquesta fou la darrera instancia presentada pels catalans a Enric IV.

1 J. Vicens Vives, Els Trastàmara, Barcelona 1956, p. 181. 
El dia 16 de juliol de 1463, les autoritats catalanes lliuraren al prior de Natzaret les instruccions i, dos dies després, els diputats escrivien la carta credencial dels ambaixadors. La missió d'aquests consistia a protestar per la sentència arbitral encomanada al rei de França (de la qual les autoritats del Principat ni tan sols havien estat informades i que, en conseqüència, consideraven nul-la), demanar la vinguda a Catalunya del germà del monarca castellà i exigir ajuda efectiva per a la guerra ${ }^{2}$. Abans, el 23 de juny, havien sortit també de Barcelona uns altres ambaixadors enviats a Lluís XI per conèixer els seus designis i gestionar, si era posible, la unificació d'alguns interessos comuns ${ }^{3}$.

Els dos enviats a Castella tenien l'ordre d'anar comunicant per carta a les autoritats del Principat el curs de les negociacions, i així degueren fer-ho, perquè els diputats contestaren a un de llurs escrits el 8 d'octubre de $1463^{4}$.

Del viatge del pare Ponç a Castella es conserva una nota de cobraments i despeses ${ }^{5}$. Heus ací, pel que fa referència a l'equip d'aquest ambaixador $\mathrm{i}$ als diners rebuts $\mathrm{i}$ gastats per ell en aquest viatge, el que ens diu aquesta nota.

En primer lloc, els diputats donaren al prior de Natzaret 302 lliures i 10 sous que, a raó de cinc florins corrents diaris (que és la dieta que la nota indica) significa que li pagaren 110 dies de viatge. El paper dels comptes diu, però, «per IIII mesos que estiguí en la desús dita embachada» i, més enllà, «quatre mesos que fuy fora de Barcelona». Si el monjo sortí de Barcelona a primers d'agost, a primers de novembre devia tornar a ser-hi.

El 7 d'octubre del 1463, els diputats escriuen als dos embaixadors i els diuen, entre altres coses: «per l'altre correu ab lo qual vos trametem la present duplicada haureu crèdit per ésser socorreguts

2 S. SOBREQUÉS I VIDAL i J. SOBREQUÉs I CALlıCó, La guetra civil catalana del segle XV. Barcelona 1973, I, p. 462.

3 Veg. J.M. MAdurELL, *Embajada catalana a Luis XI (1436-1464). Notas para su estudio», BRABLB XXXII (1967-1968), pp. 189-307.

4 CODOIN, ACA, XXIV, pp. 132-133.

5 Arxiu de Poblet, arm. I, cal. 16, núm. 370. És un bifoli de paper, alt i estret. 
aquí de diners ${ }^{6}$. Deu ser en virtut d'això que fra Ponç anota que, a Segovia, que és on era el rei de Castella, rebé d'ell, per mans del tresorer reial de l'Alcàsser, 20.000 maravedís, equivalents a 200 florins corrents, és a dir, a 110 lliures.

Quant a les despeses anteriors a la sortida de Barcelona, consistiren en la compra de tres mules, que el prior de Natzaret adquirí per 57 lliures i 15 sous, una sella de muntar i l'arranjament d'una altra, que li costaren una lliura i 9 sous, i ganivets i civada per un import de 12 sous i 6 diners. La nota diu també que mossèn Antoni Pujades i Lluís Setantí, encarregats de proveir l'ambaixador, li compraren «drap» de diverses menes, sens dubte perquè pogués viatjar bé i presentar-se dignament a Enric IV. La compra consistí en quatre canes i mitja de «bruneta de sent Johan» per a una capa (a 56 sous la cana); dues canes i mitja de «blanquet» per a una cota (a 35 sous la cana) i 3 canes de «mescla» per a una "çamarra» (a 30 sous la cana). De la seva banda, el monjo es comprà dues canes de «saya» negra per a un escapulari nou, que li costaren 20 sous, i un bonet pel qual en pagà unes altres 20 . El sastre, mestre Berenguer, cobrà una lliura i 16 sous per la confecció de les peces de vestir. Part per al viatge i part per a la seva correcta presentació a la cort castellana, el prior adquirí també un capell, guants, «borzeguins» i esperons, amb un cost total d'una lliura, 4 sous i 6 diners. Sumantho tot, la indumentària del prior valia 524 sous i 8 diners. No s'hi compta la túnica ni la cogulla: el prior de Natzaret les devia tenir a bastament noves i no li calgué fer-ne confeccionar d'altres.

Però el monjo ambaixador necessitava també, per complir amb la seva missió, tot el necessari per a escriure; el cas és que comprà «unes escrivanies» i una bossa («una bocheta») potser per posar-hi els estris d'escriure; tot plegat li costà una lliura i 7 sous. Així anava equipat també per poder complir amb el que li havien manat les autoritats del Principta: que els tingués al corrent per carta de la marxa de les negociacions.

El viatge el féu amb tres acompanyants: Francí Codina, Jaume Clasquerí i Berenguer Martí, a més d'un mosso. Als dos primers els

${ }^{6}$ CODOIN, ACA, XXIV, pp. 132-133. 
donà 115 sous, probablement per comprar coses necessàries per a la ruta, mentre que Berenguer Martí es proveí ell mateix de tot i l'ambaixador només li pagà les despeses del viatge.

Durant els quatre mesos que estigué fora de Barcelona per l'ambaixada, fra Lluís Ponç gastà, segons anota, en les quatre cavalcadures (tres de comprades i una que devia ser seva, o potser de Berenguer Martí) i el mosso, 128 lliures en despeses ordinàries, vestits del mosso, sous dels «hòmens" acompanyants esmentats, donatius $i$ altres despeses que no especifica.

De retom, els diputats li donaren, com a complement del seu salari, quelcom ${ }^{7}$ que, en ser venut, li ocasionà una pèrdua, respecte al seu valor teòric, de mil rals, és a dir, 75 lliures. La venda fou efectuada per fra Fenollar i fra Coello (el futur abat de Poblet Joan Payo Coello), mentre el pare Ponç era a Vilafranca amb el rei Pere.

Ací acaba, en la nota de fra Lluís Ponç, el relatiu a l'ambaixada prop d'Enric IV; el paper conté anotacions d'altres despeses relacionades amb petits detalls de la situació de Catalunya en aquell temps. La primera és una anotació en la qual el pare Ponç diu que donà al bosser de Poblet 15 florins que serviren «per conprar artelleria per a Poblet». Però el pare Ponç, de retorn de l'ambaixada i quan Pere de Portugal ja era, com a rei, a Catalunya, actuà també com a almoiner seu; així, a la nota que comento, consta una despesa de 18 lliures per un mosso i una mula que el prior de Natzaret mantingué durant deu mesos «per seguir los consells de la terra e servir lo rey don Pere de almoyner» 8 .

A continuació, en el paper, hi ha tres anotacions relatives a comptes del priorat de Natzaret, escrites en diversos moments. No escau de comentar-les aci.

${ }^{7}$ La nota de comptes diu exactament «les canyelles» $\mathrm{i}$ «les quals canyelles». Pot ser un error per canadelles? La lectura paleogràfica és segura i clara totes dues vegades.

8 Veg. també S. SObrequés i J. SObrequé, op. cit. II, p. 226, n. 106. 


\section{APÈNDIX}

[foli $\mathrm{Ir}$ ]

\section{H S}

Comte de tot quant é rebut per causa de la enbachada que fiu ensems ab mossèn Miquel Cardona al sereníssim senyor rey de Castella don Anrich per part de tot lo Principat de Catalunya e ciutat de Barcelona.

Primo rebí del General per iiij mesos que estiguí en la desús dita enbachada, prenent tots dies cinch florins corents cccij $11 . \mathrm{x} \mathrm{s}$.

f́tem me donà lo sereníssim senyor rey de Castella tornant-me de sa senyoria en Catalunya, per mans de Johan de la Canbra, qui tenia los tresòs de l'Alcàcer de Segòvia on lo dit rey era, xx mília maravadís, qui valen $\mathrm{CC}$ florins corents, qui pugen

Suma CCCC xij II. x s.

Cx II.

[foli 1v]

\section{HS}

Comte de les despeses fetes per mi frare Loís Ponç per causa de la enbachada desús mencionada.

Primo despenguí ans que partís de Barcelona en iijs mules que compraren Artal de Claramunt $\mathrm{e}$ Francí de Sentmenat, la primera costà xxxv flofins d'or en or, l'altra xxij, l'altra xx, que pugen totes

f́tem comprí una sella e adobí'n un-altra; costà

Ítem unes ganivetes per a tallar e civada per a les mules

ftem mosèn Anthoni Puiades e Loís Setantí qui

Lvij Il. xv s. jll. ix s. xij s. $6 \mathrm{~d}$. havien càrec de mon desenpachament, iiij $\mathrm{e}$ miga de bruneta de sent Johan per a una capa, a raó de lx sous la cana, més ij canes e miga de blancet per una cota a raó de xxxy s. la cana, més iij canes de mescla per a una çamarra a raó de xxx 1l. la cana; puja tot

Item ij canes de saya negra per a un escapolari, xx s.; un bonet, xx s. Tot

xxij II. 7s. $6 \mathrm{~d}$.

ij Il.

Suma Ixxx iiij II. iiij s. 
Ítem doní a mestre Berenguer, sastre, per les costures de tot mon vestir

ftem una bocheta e unes scrivanies costaren jll.xvjs.

f́tem capel, guants, esperons, borzeguins; tot j11. vij s.

f́tem doní als dos hòmens qui anaren ab mi, j 11. iiijs. vj d. Francí Codina e Jaume Clasquerí Cxv s., que Berenguer Martí qui anava ab mi ell matex se agué totes coses, que sols yo li feya la messió

Ítem despenguí en aquels iiij mesos que fuy fora de Barcelona ab iiij cavalcadures e un moço, axí en la despesa ordenària com en lo vestir del moço e soldades dels hòmens e donatius $\mathrm{e}$ altres estraordenaris

Ítem perdí en les canyelles que lo General me donà per compliment de pagua de tot mon salari con fuy tornat, les quals canyelles veneren frare Fenolar e frare Quello essent yo en Vilafranqua ab lo senyor rey don Pere, mil reals, que són

Item doní a frare Pau, bosser de Poblet, xv florins

qui serviren per conprar artelleria per a Poblet viij $11 . \mathrm{v} \mathrm{s}$.

f́tem sostenguí una mula e un moço a cost e messió mis $\mathrm{x}$ mesos per seguir los consels de la terra e servir lo rey don Pere de almoyner, per lo servir e útil de Poblet; pugà xviij 11.

\section{Suma CC xxxviiij II. vij s. vj}

\section{$[f .2 v]$}

Suma universal de rebudes CCCxij $11 . \mathrm{x}$ s.

Suma universal de despeses CCCxxiij II. xj s. vj

Resta envés mi lxxxviij II. xviij s. vj

Costà'm la hobra de la nostra cambra segons apar per menut en mon comte xxij 11. xij s.

per què resta envés mi

É despès més que no e rebut en la administració de v 11. $\mathrm{xv} \mathrm{s}$. Ixx 11 . la casa de Natzaret, segons per mos comtes se mostra clarament e per menut lxxx 11. e més, les quals quytanta [sic] II. jamés me an volgut restitoir ne oir los comtes, axí que fins a iij de deembre any MCCCC Ixxiij é yo més despès que no rebut 
xiij 1l. xiij $x . v j$

Pos en despesa la obra que he posada en la cambra on de present estich, que són xxxxiiij 11 .

Costaren les cortines, axí de la cambra com del xviiijs. i i ij estudi xj Il. xv s. i j

Suma lvj Il. xiiij s, vj 